\title{
Morphological sensitivity in deaf readers of Dutch
}

\author{
ANNE H. VAN HOOGMOED, LUDO VERHOEVEN, \\ ROBERT SCHREUDER, and HARRY KNOORS \\ Radboud University Nijmegen
}

ADDRESS FOR CORRESPONDENCE

Anne H. van Hoogmoed, Faculty of Social Sciences, Behavioural Science Institute, Radboud

University Nijmegen, Nijmegen 6500 HE, The Netherlands. E-mail: a.vanhoogmoed@ donders.ru.nl

\begin{abstract}
Deaf children experience difficulties with reading comprehension. These difficulties are not completely explained by their difficulties with the reading of single short words. Whether deaf children and adults lag behind in the morphological processing of longer words is therefore examined in two experiments in which the processing of prefixes by deaf versus hearing children and deaf versus hearing adults is compared. The results show that the deaf children use morphological processing but to a lesser extent than hearing children. No differences appeared between the deaf and hearing adults. Differences between deaf children with and without a cochlear implant were examined, but no firm conclusions could be drawn. The implications of the results for the reading instruction of deaf children are discussed.
\end{abstract}

Deaf children experience considerable difficulties with reading comprehension (e.g., Traxler, 2000; Wauters, van Bon, \& Tellings, 2006). The reading comprehension delays of deaf children cannot be completely explained by problems with single word reading as this has been found to be fairly intact in deaf children (Burden \& Campbell, 1994; Kuo \& Anderson, 2006; Wauters et al., 2006). However, the studies of deaf children's single word reading have examined almost exclusively monomorphemic words. Problems with the decoding of longer, polymorphemic words and thus the use of morphology for purposes of word identification may contribute to the delays observed in deaf children's reading comprehension. The purpose of the present research was therefore to investigate whether the comprehension delays of deaf readers can be explained at least in part by morphological processing problems encountered during their word reading. In the following, we will first explain what morphology is and then review the relevant research with regard to the morphological processing of hearing versus deaf readers.

Morphology is the study of morphemes, which are the smallest word parts that carry meaning. In Germanic languages like English and Dutch, there are several forms of morphology including inflection, derivation, and compounding.

(c) Cambridge University Press 2011 0142-7164/11 \$15.00 
van Hoogmoed et al.: Deaf readers' processing of inflectional prefixes

Inflection is the addition of affixes to base words to express grammatical contrasts (e.g., cat vs. cats, create vs. created). Derivation is the addition of affixes to base words to create new words (e.g., farm vs. farmer, baker vs. bakery). Compounding is the combination of two or more base words to create a new word (e.g., news plus paper to form newspaper, wind plus mill to form windmill). For inflection and derivation, two types of affixes can be added to base words (e.g., prefixes placed at the beginning of the base word and suffixes placed at the end of the base word).

The use of morphology in word reading depends upon the frequency of a word (Baayen, Dijkstra, \& Schreuder, 1997) and the reader's level of experience. If a word is frequent and/or better known by the reader, he or she should be able to identify the word immediately and thus without morphological processing. Infrequent or unfamiliar words cannot be identified immediately from storage and therefore require morphological decomposition. However, this depends not only on the frequency of the complete word but also on the occurrence of the affix. If the affix does not occur frequently, words with this affix are assumed to be stored as a whole rather than computed by identifying the morphemes (Bertram, Schreuder, \& Baayen, 2000).

A number of studies have investigated the relation between the morphological analysis of words and measures of reading in hearing children. The proficiency in analyzing morphologically complex words has been shown to be related to word reading proficiency and reading comprehension in English-speaking children in the first through sixth grade (Carlisle \& Fleming, 2003; Mahony, Singson, \& Mann, 2000; Singson, Mahony, \& Mann, 2000), as well as in French-speaking children from kindergarten through second grade (Casalis \& Louis-Alexandre, 2000). In addition, research has shown that hearing children in Grades 3 to 6 use morphological processing during word reading in English (Carlisle \& Stone, 2005), as do Dutch third- to sixth-grade children in reading Dutch words (Verhoeven, Schreuder, \& Haarman, 2006).

The question now is to what extent morphology may play a role in the word reading of deaf children. In 1967 Cooper compared the inflectional and derivational knowledge of deaf and hearing children and adolescents between 7 and 19 years of age and found the morphological awareness of the deaf children in general to lag as much as 6 years behind that of the hearing children. Derivation appeared to be more difficult than inflection for both the deaf and hearing children, and the deaf children showed a greater lag for derivation than for inflection. Subsequently, Hanson (1993) studied the use of morphology to learn the (given) meaning of pairs of pseudowords by deaf college students. The learning of pairs of pseudowords proved faster when semantically related words (e.g., book and read) were associated with derivationally related pseudowords (e.g., ralp and ralpify) as opposed to derivationally unrelated pseudowords. It was concluded that the deaf subjects appreciated that the orthographic and phonological overlap of the pseudoword root, combined with the derivational suffix could be related to semantic overlap, which confirms the presence of morphological awareness on the part of the deaf college students. Gaustad, Kelly, Payne, and Lylak (2002) similarly demonstrated morphological awareness on the parts of both deaf college students and deaf middle school students although the level of their awareness clearly lagged behind 
that of hearing students. In a follow-up study when Gaustad and Kelly (2004) matched deaf and hearing students for reading ability, only a small difference was found between the students for easier tasks that required them to segment words and indicate the meaning of words with one inflectional suffix or derivational affix. In contrast, the deaf students performed significantly below the level of hearing students on complex words with two or more bound morphemes (e.g., "dis-in-fect-ant," "re-in-force-ment"). It can thus be concluded that deaf readers are able to analyze morphologically complex words to some extent, but are not as proficient as their hearing agemates.

The above studies were all conducted in English. These results may not be generalizable to Dutch, because English and Dutch differ in morphological complexity (Kemps, Wurm, Ernestus, Schreuder, \& Baayen, 2005). Furthermore, all studies looked at the ability to analyze morphologically complex words, but not whether morphological processing is used during word reading. As far as we know, no research has been conducted as yet upon morphological processing during word reading by deaf children.

What is known about the reading comprehension of deaf children is that a general delay tends to exist (Traxler, 2000; Wauters et al., 2006). This is not surprising, because deaf children have limited access to spoken language and "have fewer fluent and competent adult language models attuned to their communication needs" (Gaustad et al., 2002, p. 7).

In recent years, more deaf children have been given a cochlear implant (CI) than in the past. After the implantation of such a device, speech perception has been found to increase substantially for many deaf children (Meyer, Svirksy, Kirk, \& Miyamoto, 1998; Robbins, Koch, Osberger, Zimmerman-Phillips, \& KishonRabin, 2004). As a result of this improvement, both the spoken language development and reading development of these children may differ from that of deaf children who have not received a CI. The results of reading studies with children with a CI, for example, show the same reading problems as for deaf children without a CI but less severe. When Geers (2003) studied the reading comprehension of deaf children without a CI, children with a CI, and hearing 8or 9-year-old children, she found the children with a CI to perform better than the deaf children at the age of 9 years; but, even when implanted early, half of the children with a CI to still show significant reading comprehension delays relative to the hearing children. Vermeulen, van Bon, Schreuder, Knoors, and Snik (2007) also recently showed children and young adults between 7 and 23 years of age with a CI to experience reading comprehension problems; the problems were clearly less severe than those of deaf children without a CI, however, and the word recognition skills of the children with a CI were found to be in line with those of hearing age mates.

On the basis of the findings reviewed above, it appears that the reading comprehension problems of deaf children and children with a CI cannot be fully explained by problems with the reading of words. In the aforementioned studies, however, the identification of short, mostly monomorphemic words, was studied, which means that the comprehension delays of deaf readers may still be explained by problems with the decoding of longer, polymorphemic words. To date, however, no 
research has been conducted on the use of morphological processing during word reading of deaf readers. In the following experiment, the use of morphological processing for purposes of word reading by deaf and hearing children was therefore studied experimentally. The morphological processing abilities of deaf children were expected to lag behind those of their hearing peers. However, deaf children's morphological processing was expected to eventually reach the same level as that of hearing adults. For this reason, a second experiment was conducted with deaf and hearing adults, in which morphological processing was studied at the adult level.

\section{EXPERIMENT 1}

In this experiment, the goal was to study the processing of morphological inflection by both deaf and hearing children because inflection is much more productive and transparent in Dutch than derivation (Booij, 2002). The focus was on inflectional prefixes in an adaptation of the study conducted by Verhoeven er al. (2006) on the identification of real and pseudoprefixes by hearing children and adults. All of the target words in that experiment started with the syllable "ge" or "be." Depending upon whether the first syllable in such words is an inflectional prefix or not, however, the pronunciation of the letter "e" differs in Dutch. In a word that starts with an actual inflectional prefix, stress is placed upon the second syllable of the word. In words such as "gezegd" (said), which is the past participle of "zeggen"

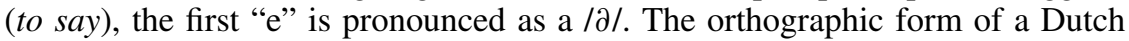
prefix may have the same phonology (phonological prefix), as in the word "gezin" (family), but it may also have a different phonology (pseudoprefix). In the latter case, the first syllable is stressed and the " $\mathrm{e}$ " in that syllable is pronounced as an $/ \varepsilon /$ or /e/ (e.g., "gevel" = façade or building front). Verhoeven et al. (2006) compared the identification of words with real prefixes and phonological prefixes (i.e., same orthography and phonology as real prefix) with the identification of words with so-called pseudoprefixes (i.e., same orthography but different phonology as real prefix) in a lexical decision task and found the words with a real prefix or phonological prefix to be retrieved more quickly and accurately than the words with a pseudoprefix. The conclusion was that not only hearing adults but also hearing children use morphological processing to read individual words. However, when the responses to the different prefixes were examined separately, the effect was found to be significant for only those words with the more frequent prefix /g $/$ and not for those words with the less frequent prefix $/ \mathrm{b} \partial /$.

In the current experiment, the study of Verhoeven et al. (2006) was thus adapted to examine the extent to which deaf children use inflectional morphology for purposes of word reading. The expectation was that the deaf children would lag considerably behind their hearing age mates with regard to both general reading level and morphological processing because the deaf children have little or no access to Dutch morphology until they begin to read. That is, early morphological processing cannot facilitate the word reading of deaf children. In addition to the main question of whether differences exist in the use of morphological processing for purposes of word reading by hearing versus deaf children, whether or not a 
significant difference is detected for the use of morphological processing by deaf readers with versus without a CI was also investigated. Our expectation was that deaf readers with a CI would make more use of morphological processing than deaf children without a CI but that the level of morphological processing for the deaf readers with a CI would nevertheless lag behind that for hearing children given the limited access to spoken language before implantation.

\section{Method}

Participants. Twenty-five sixth-grade deaf children (mean age $=11$ years, 11 months $[11 ; 11]$ ) were recruited from schools for deaf children in The Netherlands. The children all had intelligence profiles in the normal range and no additional disabilities. They were all born deaf or gone deaf before the age of 3 . Of the 25 participating deaf children, 10 had a CI and the remaining 15 had no CI. The mean age of cochlear implantation was $5 ; 10$ (range $=3 ; 01-11 ; 05$ ). According to the teachers of the deaf children, most of the children without a CI used sign language in combination with spoken language at school, whereas most of the children with a CI switched between this combined signed and spoken language and sign-supported spoken Dutch, in which spoken Dutch, including Dutch syntax, is supported by signs. According to their teachers, four of the children without a CI could not understand any spoken language; five could understand some words via lipreading; five could understand a sentence via lipreading; and one could follow an entire conversation via lipreading. Five of the children with a CI could understand some words via lipreading; four could understand a sentence via lipreading; and one could follow an entire conversation via lipreading. None of the children could understand spoken language without some lipreading.

As a comparison group, 43 sixth-grade hearing children (mean age $=11 ; 06$ ) and 50 third-grade hearing children (mean age $=8 ; 05$ ) were also recruited to participate in the present study. We expected the reading comprehension level and reading vocabulary of the third-grade children to be more or less equal to the reading level of the deaf children who were 3.5 years older on average. All the hearing children were native speakers of Dutch and were recruited from regular schools in the east of The Netherlands.

Stimuli and design. Four sets of bisyllabic words containing the letter " $\mathrm{e}$ " in the first syllable position were constructed for this experiment (see Appendix A). Two sets started with the syllable "ge" and two sets started with the syllable "be"; these two particular prefixes were chosen because they clearly differ in frequency. In both type and token counts from the Celex database for Dutch, the prefix /g 2 / is more frequent than the prefix /b2/ (Baayen, Piepenbrock, \& Gulikers, 1995). Similarly, the prefix /g $/$ / is more frequent relative to the pseudoprefix /ge/ (the prefix /g $\partial /$ occurs in $90 \%$ of those words starting with "ge") than the prefix /b $\partial /$ is frequent relative to the stressed pseudoprefix /be/ as counted in the Celex database (Baayen et al., 1995).

One set of stimuli consisted of 10 words starting with the real or phonological prefix /g $/$ / (e.g., the word "gebaar" [sign] or "gebit" [teeth]). Another set of stimuli 
contained 10 words starting with the real or phonological prefix /b $\partial /$ (e.g., the word "bedrag" [amount] or "bewijs" [proof]). A third set of stimuli consisted of 5 words starting with the pseudoprefix /ge/ (e.g., the word "gevel" [front] or "gever" $[=$ giver $]$ ). No more suitable words for this category were available in Dutch. A final set of stimuli contained 10 words starting with the pseudoprefix /be/ (e.g., the word "bever" [beaver] or "beter" [better]). Two groups of control (i.e., filler) words without a prefix were included (see Appendix A). The first group of 20 control words contained first-syllable stress in concordance with those target words with a pseudoprefix (e.g., "tafel" [table] or "eikel" [acorn]). The second group of control words contained 15 words with stress on the last syllable in concordance with those target words with a real or phonological prefix (e.g., "banaan" [banana] or "sigaar" [ cigar]). All of the item subsets were matched with regard to mean length (range $=5.20-5.53)$, surface frequency $\left(\log\right.$-frequency ${ }^{1}$ means $\left.=1.06-1.33\right)$, lemma frequency (log-frequency means $=1.32-1.66)$, and bigram frequency (means $=7.14-7.60)$ using the CELEX database on written language (Baayen et al., 1995). For each of the words, a pseudoword was also derived by changing two letters in the stem of the item. These pseudowords were also matched to the test words with respect to mean length (range $=5.50-5.52)$ and bigram frequency (means $=7.14-7.25)$. All of the items were pseudo randomized in such a manner that no more than three stimuli of the same type (i.e., word or pseudoword) occurred consecutively.

Procedure. The children were tested individually in a separate room at school. A laptop was used to administer the lexical decision task. ${ }^{2}$ The children were presented 10 practice trials before the experimental trials began. After each practice trial, feedback was provided. After all the practice trials, the children were told that the test was going to start and that they would not be given anymore feedback.

The letter strings were presented in white on a black screen ( 76 point Courier New Bold). First, a fixation point was presented for $750 \mathrm{~ms}$ (also 76 point Courier New Bold). After a 250-ms blank screen, the test letter string appeared until the participant responded. When a participant did not respond within $4000 \mathrm{~ms}$, the letter string disappeared. After that, the participants still had $1000 \mathrm{~ms}$ to press a button, before the next fixation point showed up.

The items for this experiment were mixed with the items for other experiments. The participants were presented a total of 360 stimuli in two sessions with 180 stimuli each. Each session was split into two blocks of equal size, which were separated by a break. The break lasted a maximum of $5 \mathrm{~min}$; the participant could continue sooner by pressing a button. One session lasted a total of about $15 \mathrm{~min}$, including the break.

\section{Results}

Deaf versus hearing children. Table 1 presents the mean reaction times and accuracy scores for the four sets of target words. Reaction times were calculated only based on correct responses. The deaf children with and without a CI were 
van Hoogmoed et al.: Deaf readers' processing of inflectional prefixes

Table 1. Reaction time (RT) and accuracy scores of child word identification as a function of prefix category

\begin{tabular}{|c|c|c|c|c|c|c|}
\hline & \multicolumn{3}{|c|}{ RT (ms) } & \multicolumn{3}{|c|}{ Accuracy } \\
\hline & $\begin{array}{c}\text { 3rd-Grade } \\
\text { Hearing }\end{array}$ & $\begin{array}{l}\text { 6th-Grade } \\
\text { Hearing }\end{array}$ & $\begin{array}{l}\text { 6th-Grade } \\
\text { Deaf }\end{array}$ & $\begin{array}{c}\text { 3rd-Grade } \\
\text { Hearing }\end{array}$ & $\begin{array}{c}\text { 6th-Grade } \\
\text { Hearing }\end{array}$ & $\begin{array}{c}\text { 6th-Grade } \\
\text { Deaf }\end{array}$ \\
\hline /gд/ words & $1550(558)$ & 1175 (237) & 1225 (349) & $.93(.11)$ & $.98(.05)$ & $.73(.25)$ \\
\hline /ge/ words & $1905(755)$ & $1377(364)$ & $1197(318)$ & $.40(.21)$ & $.82(.21)$ & $.48(.26)$ \\
\hline /b $\partial /$ words & $1705(517)$ & $1231(291)$ & $1215(269)$ & $.79(.19)$ & $.96(.06)$ & $.55(29)$ \\
\hline /be/ words & $1620(470)$ & $1235(296)$ & $1201(328)$ & $.78(.15)$ & $.95(.07)$ & $.74(.21)$ \\
\hline
\end{tabular}

treated as a single group in these analyses as the group sizes would otherwise be too small (i.e., 10 with CI, 15 without CI). In a separate set of analyses reported on below, however, the differences between those deaf children with a CI and those without a CI are considered. The speed and accuracy of the hearing versus deaf children's responses were compared in separate analyses of variance (ANOVAs) with group as a between-subjects factor (third-grade hearing, sixth-grade hearing, and sixth-grade deaf) and word category as a within-subjects factor (/g $/ /, / g e /$, /b2/, and /be/).

The reaction time results revealed an effect of word category, $F(3,111)=9.18$, $p<.001$, an effect of group, $F(2,113)=20.43, p<.001$, and an interaction between word category and group, $F(6,222)=2.31, p=.035$. Similarly, the analyses of the accuracy of the children's responses revealed an effect of group, $F(2,115)=61.33, p<.001$, an effect of word category, $F(3,113)=58.68$, $p<.001$, and an interaction between the two, $F(6,226)=15.77, p<.001$. Post hoc analyses showed that, in general, the sixth-grade deaf children and sixthgrade hearing children respond faster than the third-grade hearing children in all word categories. For accuracy, significant differences between the groups were detected: the sixth-grade hearing children were more accurate than the sixthgrade deaf children while the accuracy of third-grade hearing children differed per category compared to the other groups.

Given the significant interactions in the ANOVAs, specific contrasts were undertaken for each group separately. The reaction times and accuracy of the children's responses for the four categories of words are depicted in Figure 1. As can be seen for the speed of the children's responses, the sixth-grade hearing children and third-grade hearing children were faster on words with a real or phonological prefix $/ \mathrm{g} \partial /$ than on words with a pseudoprefix /ge/ $(p=.001$ and $p<.001$, respectively). In contrast, the sixth-grade deaf children did not show significant differences in the speed of their responses to these categories $(p=.782)$. The third-grade hearing children were faster on words with the pseudoprefix /be/ than on words with the real or phonological prefix $/ \mathrm{b} \partial /(p=.011)$, whereas the sixthgrade hearing and sixth-grade deaf children did not show such differences $(p=$ .934 and .383 , respectively). 


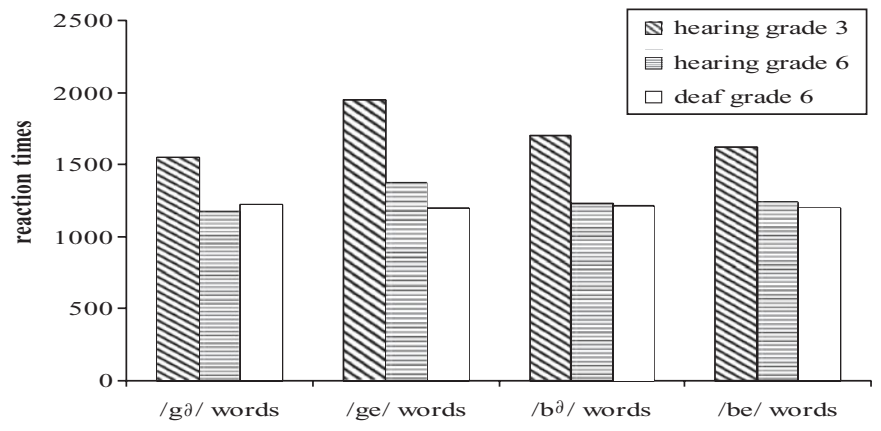

(a)

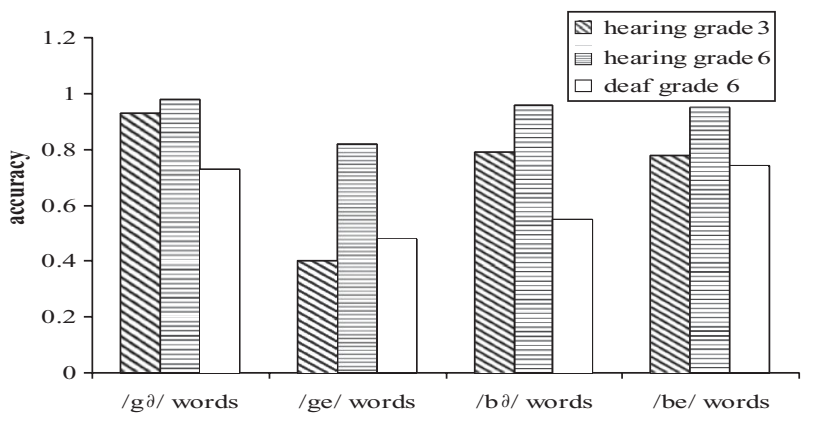

(b)

Figure 1. The (a) speed and (b) accuracy of children's responses to words with real prefixes and pseudoprefixes.

As can be seen for the accuracy of the children's responses to the different word categories (see Figure 1b), significant differences were found for the words with the real prefix /ga/ versus the pseudoprefix /ge/ for all three groups of children (all $p s<.001)$. All groups of children responded more accurately to the words with the real prefix /ga/ than to the words with the pseudoprefix /ge/. The deaf children also differed with respect to the accuracy of their responses to words with the real prefix /b2/ versus the pseudoprefix /be/ $(p<.001)$, although their responses to the words with the pseudoprefix were more accurate than their responses to the words with the real prefix. The accuracy of the third- and sixth-grade hearing children's responses did not differ significantly for these categories (both $p \mathrm{~s}>.5$ ).

Deaf children with and without $\mathrm{Cl}$. To test for differences in the speed and accuracy of the performance of the deaf children with and without a CI, two ANOVAs were conducted with group (with $\mathrm{CI}$ and without $\mathrm{CI}$ ) as a between-subjects factor and word category (/g $\partial /, / \mathrm{ge} /, / \mathrm{b} \partial /$, and /be/) as a within-subjects factor. No significant reaction time differences were found. For accuracy, an effect of word category, $F$ $(3,21)=15.89, p<.001$, was found but no effect of group and no significant interaction. 
In light of the specific expectations that we had with regard to the /g $\partial /$ and /ge/ categories and the /b $\partial /$ and /be/ categories, the responses to these categories was also analyzed for the two groups. The only marginal significant difference showed up for the reaction times on the /b2/ versus /be/ words. Children without a CI responded faster to words with the pseudoprefix /be/ (reaction time $=$ $1119 \mathrm{~ms}$ ) than words with the real prefix $/ \mathrm{b} \partial /$ (reaction time $=1247 \mathrm{~ms}, p=.070)$, whereas no significant differences were detected for the children with a CI (reaction time $=1246$ and $1170 \mathrm{~ms}$, respectively).

\section{Conclusions}

In general, the sixth-grade hearing and sixth-grade deaf children reacted faster to words than the third-grade hearing children. Post hoc analyses further showed the hearing children to respond faster to words with the prefix /g $\partial /$ when compared to words with the pseudoprefix /ge/, whereas the deaf children did not show such a difference.

In general, the sixth-grade hearing children responded more accurately than the sixth-grade deaf children. This difference in the accuracy of the children's responses is most likely due to their word knowledge, as no such accuracy differences were found for the responses of the deaf and hearing children to pseudowords (which are not presented in this article). Post hoc analyses showed all of the deaf and hearing children to respond more accurately to the /g $/$ / words than to the /ge/ words. For the words starting with /bz/ prefix, no beneficial effect of the prefix was found. The responses of the deaf children were even more accurate for the words with the /be/ pseudoprefix than for the words with the real /bz/ prefix. In sum, deaf and hearing children appear to use morphological processing for purposes of word recognition but only when the word starts with the more frequent prefix /g $\partial /$.

Few differences in the performance of the deaf children with or without a CI were detected. The only marginally significant difference entailed the deaf children without a CI responding faster to words with the pseudoprefix /be/ than to the words with the real prefix /b2/. The deaf children with a CI did not show such a difference. This suggests that both groups of deaf children did not use the real /bz/ prefix for recognition of such words. The lack of further significant differences between the two groups of deaf children may be due to a lack of power as there were few children in both of the groups.

\section{EXPERIMENT 2}

We expected that although deaf children are behind their hearing age mates, they might have caught up in reading polymorphemic words in adulthood. It could be that deaf adults even use greater morphological processing than hearing adults because deaf adults may have fewer words stored in their lexicons than hearing adults. As a result, deaf adults may have to apply morphological processing for purposes of word reading to a larger extent than hearing adults. However, it may also be that they use less morphological processing, because they might know less base words and affixes than hearing adults, which makes morphology less useful 
van Hoogmoed et al.: Deaf readers' processing of inflectional prefixes

Table 2. Reaction time (RT) and accuracy of adult word identification as a function of prefix category

\begin{tabular}{|c|c|c|c|c|}
\hline & \multicolumn{2}{|c|}{ RT (ms) } & \multicolumn{2}{|c|}{ Accuracy } \\
\hline & Deaf & Hearing & Deaf & Hearing \\
\hline /gd/ words & 854 (181) & $658(95)$ & $.99(.03)$ & $.97(.06)$ \\
\hline /ge/ words & $920(245)$ & 732 (109) & $.92(.15)$ & $.80(.22)$ \\
\hline /bə/ words & $845(171)$ & $685(83)$ & $1.00(.00)$ & $.97(.07)$ \\
\hline /be/ words & $888(213)$ & 679 (107) & $.98(.04)$ & $.97(.07)$ \\
\hline
\end{tabular}

in decoding words. To determine what the adult level of morphological processing in deaf readers is, a second experiment was undertaken.

\section{Method}

Participants. Participants were 25 deaf adults (mean age $=46 ; 10$ ), and 30 hearing adults (mean age $=22 ; 0$ ). The deaf adults were recruited via several organizations for deaf people in The Netherlands. Two of the deaf adults had a CI, 8 had a hearing aid, and 15 had no hearing device. All of the deaf adults had at least vocational high school. The hearing adults were mostly undergraduates from the University of Nijmegen.

Stimuli and design. The stimuli and research design were the same as in Experiment 1.

Procedure. The procedure was almost the same as in Experiment 1. The deaf adults were either tested in their homes or in a separate room at their work. The hearing adults were tested in a separate room at the university. The two parts of the experiment lasted about $10 \mathrm{~min}$ as opposed to $15 \mathrm{~min}$ each because of the faster responses on the part of the adults relative to the children.

\section{Results}

Table 2 provides the mean adult reaction times and accuracy scores for the four sets of words. Two separate ANOVAs were conducted on the speed and accuracy of adult responses with group (deaf or hearing) as a between-subjects factor and word category as a within-subjects factor. For the speed of responding, an effect of group, $F(1,53)=26.21, p<.001$, and an effect of word category, $F(3,41)=$ $7.18, p<.001$, was found but no interaction between the two factors. Similarly, for the accuracy of the responses, an effect of group, $F(1,53)=8.23, p=.006$, and an effect of word category, $F(3,41)=7.38, p<.001$, was found but no interaction between the two factors. In general, the hearing adults were faster than deaf adults but the deaf adults more accurate. 
van Hoogmoed et al.: Deaf readers' processing of inflectional prefixes

When the specific contrasts were analyzed for the two groups independently, only a significant difference between the /g $\partial /$ and /ge/ words was found for the hearing adults $(p<.001)$. The prefixed /g $/$ words were responded to more accurately than the pseudoprefixed /ge/ words.

\section{Conclusions}

In general, the hearing adults responded faster to the presented words than the deaf adults, but the deaf adults responded more accurately. This difference may be due to different task orientations on the part of the participants. The deaf adults may have had the desire to perform as accurately as possible and thereby prove themselves to be as good readers as hearing adults. The hearing adults may have adhered more to the task, which was to respond as quickly and accurately as possible to the presented items. Minimal effects of morphological processing were found; the hearing adults responded more accurately to the words with the real prefix /g $\partial /$ than to the words with the pseudoprefix /ge/. The few differences may possibly be due to ceiling effects because the performance of the hearing and deaf adults was generally quite good. It is also conceivable that most of the presented words were already stored in the lexicons of the adults and that this thus precluded the need to process the words morphologically.

\section{GENERAL DISCUSSION}

The results of the first experiment show both deaf and hearing children to utilize morphology to read words with the real prefix /g $\partial /$ but not words with the real prefix $/ \mathrm{b} \partial /$. The deaf children showed only differences in the accuracy of their responding, whereas the hearing children showed differences in both the speed and accuracy of their responding. It thus appears that the hearing children make greater use of morphological processing for purposes of word recognition than deaf children. The results for the hearing children with the real prefix /g $\partial / \mathrm{resemble}$ the results of Verhoeven et al. (2006); the results for the real prefix /bo/ differ, however. The accuracy scores for the real prefix /b $\partial /$ were similar in the two studies but much better for the pseudoprefix /be/ in the present study than in the Verhoeven et al. (2006) study. The difference between results on the real prefix /g $\partial /$ and real prefix /b $\partial /$ can be attributed to the difference in frequency of the prefix (Baayen et al., 1995).

In contrast to the children, the deaf and hearing adults appeared to make relatively little use of morphology. This interaction between children and adults also showed up when we performed one analysis on the accuracy of the sixthgrade children and adults together. A three-way interaction between category (/ge/ vs /g $/$ /), age group, and deaf/hearing showed up in this analysis, $F$ (1, $119)=4.668, p=.033$, because there is a difference in accuracy on /g $/$ words between deaf and hearing children, but not between deaf and hearing adults. This lack of effect in adults could be due to the length of the words used in the present experiment (i.e., words of only five to six letters) and the frequency in which they occur. Such short and frequent words may be stored as wholes in the lexicons of experienced readers and thereby minimize the need for 
morphological processing. The absence of accuracy effects could also be due to ceiling effects.

A difference in the accuracy of the responding of the deaf versus hearing children to words (but not pseudowords) was found. This difference could be due to small spoken and therefore also small written language lexicons on the part of the deaf children, given that reading optimally builds upon spoken language (Perfetti \& Sandak, 2000). Deaf children will thus respond to more words as not existing than hearing children because the deaf children do not know the meaning of the words. Comparison of the results for the deaf children to the results for the deaf adults, however, shows the deaf adults to apparently catch up as they gain reading experience.

Note that the deaf adults in the present study were mostly experienced readers, which makes it plausible that they have stored representations similar to those of hearing readers. This is nevertheless not likely to be the case for all deaf readers. The deaf adults in the present research were also mostly raised with spoken language, whereas the deaf children have been mostly raised with sign language or a combination of sign and spoken language. The results for the adults in the present study may therefore not fully predict the final state of morphological processing for deaf children.

An intriguing question is what the effects of cochlear implantation on morphological processing are. Because of small sample size, the deaf children with and without a CI were initially treated as a single group. When additional analyses were performed for the deaf children with a CI versus those without, only minimal differences were detected. More far-reaching conclusions cannot be drawn on the basis of these results due to a lack of power, however; there were only few children in each group. It is nevertheless possible that the relatively late age of implantation, at least according to current standards, may have impeded the development of proficient speech perception and thus explain the minimal differences found between the deaf children with a CI and without a CI.

At this point, some possible limitations of the present study can be mentioned. First, the children were recruited from schools, whereas the adults volunteered to participate. The group of deaf adults may therefore not be representative of the population of deaf adults in The Netherlands. It is likely, for example, that only those deaf readers who are good readers were interested in taking part in the present study. Second, the number of deaf children participating in the present study was very small, particularly for a comparison of those who have had a CI and those who have not. Those with CI also did not constitute a random sample of such children as many of the children were implanted relatively late and almost all of them were recruited from schools for special education. There are also children with a CI in regular education, and these children tend to be better readers than those in special education. Given that more and more children are currently being given a CI, it is important that greater insight is gained into possible differences in the use of morphological processing by these versus children with no such implant. Third, in the present study both real prefixes and phonological prefixes were used in one and the same experimental condition. It can be recommended to separate the two types of word forms in order to explore the role of semantics in complex word reading. 
In this study, we also did not look at individual differences and the relation between word reading proficiency and morphological processing within groups. More research on this topic is merited as well.

The finding that deaf children apply at least some morphological processing for the purpose of word reading has some practical implications. Because the use of phonology is very difficult for deaf children, because they cannot map the letters onto the sounds, it might be useful to teach them morphological processing as part of their reading instruction. This has also been stated by Gaustad (2000), who argued that deaf children should be taught so-called morphographic analysis for purposes of word identification. Morphographic analysis calls for deaf readers to visually analyze printed input into meaningful segments (i.e., morphemes). Gaustad outlined a method for learning this that parallels Frith's model for learning to decipher the printed code of English. In this model, there are three stages for learning to read: the logographic stage in which children can "read" some words but are not yet able to analyze words, the alphabetic stage in which children can identify the elements of a word element by element, and the orthographic stage in which skilled readers can analyze words into larger orthographic units. Parallel to this, the morphographic strategy for learning to read also entails three stages. In the first stage, the meaning of a word is learned directly from the visually printed word. In the second stage, the components (i.e., morphemes) in a word are identified and given their meaning. In the third stage, the combination of visual and segmental processing (i.e., wholistic and morphological) approximates word-specific orthographic processing. Although the present study provides some support for the adoption of such an approach, more research, including intervention studies, is needed to understand the relevant processes in sufficient detail. 


\section{APPENDIX A}

Table A.1. Words used in the experiments

\begin{tabular}{|c|c|c|c|c|c|}
\hline \multirow[b]{2}{*}{ lg $\partial /$-words } & \multirow[b]{2}{*}{ /bə/-words } & \multirow[b]{2}{*}{ /ge/-words } & \multirow[b]{2}{*}{ /be/-words } & \multicolumn{2}{|c|}{ Control Words } \\
\hline & & & & First Stressed & Second Stressed \\
\hline Gebaar (sign) & Bedrag (amount) & Gevel (building front) & Beker (cup) & Aarde (earth) & Adres (address) \\
\hline Gebak (cake) & Begin (start) & Gevels (fronts) & Bekers (cups) & Aardig (nice) & Alarm (alarm) \\
\hline Gebit (set of teeth) & Behang (wallpaper) & Geven (to give) & Benen (legs) & Asbak (ashtray) & Alvast (already) \\
\hline Gehakt (hamburger) & Beheer (administration) & Gever (giver) & Beren (bears) & Deksel (lid) & Banaan (banana) \\
\hline Geluk (luck, joy) & Beleg (sandwich filling) & Gevers (givers) & Beter (better) & Dokter (doctor) & Hotel (hotel) \\
\hline Gemak (ease) & Besmet (contaminated) & & Beven (to shiver) & Eikel (acorn) & Kanaal (canal) \\
\hline Gemist (missed) & Beton (concrete) & & Bevend (shivering) & Folder (leaflet) & Kapot (broken) \\
\hline Gepast (exact) & Bevel (order) & & Bever (beaver) & Giftig (poisonous) & Kopie (copy) \\
\hline Geteld (counted) & Bewijs (proof) & & Bezem (broom) & Hamer (hammer) & Metaal (metal) \\
\hline \multirow[t]{11}{*}{ Gezin (family) } & Bezit (property) & & Bezig (busy) & Heide (heather) & Ovaal (oval) \\
\hline & & & & Helder (clear, bright) & Raket (rocket) \\
\hline & & & & Hoedje (little hat) & Rivier (river) \\
\hline & & & & Jarig (have birthday) & Sigaar (cigar) \\
\hline & & & & Kapsel (haircut) & Tekort (shortage) \\
\hline & & & & Kikker (frog) & Verbod (prohibition) \\
\hline & & & & Koning (king) & \\
\hline & & & & Nodig (necessary) & \\
\hline & & & & Oever (river bank) & \\
\hline & & & & Peper (pepper) & \\
\hline & & & & Tafel (table) & \\
\hline
\end{tabular}


van Hoogmoed et al.: Deaf readers' processing of inflectional prefixes

\section{NOTES}

1. Log frequency is based on $10 \mathrm{log}$.

2. We thank H. Voogd for availing us the lexical decision task created by the Electronic Research Group from the Nijmegen Institute for Cognition and Information at Radboud University Nijmegen.

\section{REFERENCES}

Baayen, H. R., Dijkstra, A. F. J., \& Schreuder, R. (1997). Singulars and plurals in Dutch: Evidence for a parallel dual route model. Journal of Memory and Language, 37, 94-117.

Baayen, H. R., Piepenbrock, R., \& Gulikers, L. (1995). The CELEX lexical database [CD]. Philadelphia, PA: University of Pennsylvania, Linguistic Data Consortium.

Bertram, R., Schreuder, R., \& Baayen, R. H. (2000). The balance of storage and computation in morphological processing: The role of word formation type, affixal homonymy, and productivity. Journal of Experimental Psychology: Learning, Memory, and Cognition, 26, 419-511.

Booij, G. (2002). The morphology of Dutch. Oxford: Oxford University Press.

Burden, V., \& Campbell, R. (1994). The development of word-coding skills in the born deaf: An experimental study of deaf school-leavers. British Journal of Developmental Psychology, 12, 331-349.

Carlisle, J. F., \& Fleming, J. (2003). Lexical processing of morphologically complex words in the elementary years. Scientific Studies of Reading, 7, 239-253.

Carlisle, J. F., \& Stone, C.A. (2005). Exploring the role of morphemes in word reading. Reading Research Quarterly, 40, 428-449.

Casalis, S., \& Louis-Alexandre, M.-F. (2000). Morphological analysis, phonological analysis and learning to read French: A longitudinal study. Reading and Writing, 12, 303-335.

Cooper, R. L. (1967). The ability of deaf and hearing children to apply morphological rules. Journal of Speech and Hearing Research, 10, 77-86.

Gaustad, M. G. (2000). Morphographic analysis as a word identification strategy for deaf readers. Journal of Deaf Studies and Deaf Education, 5, 60-80.

Gaustad, M. G., \& Kelly, R. R. (2004). The relationship between reading achievement and morphological word analysis in deaf and hearing students matched for reading level. Journal of Deaf Studies and Deaf Education, 9, 269-285.

Gaustad, M. G., Kelly, R. R., Payne, J. A., \& Lylak, E. (2002). Deaf and hearing students' morphological knowledge applied to printed English. American Annals of the Deaf, 144, 320-324.

Geers, A. E. (2003). Predictors of reading skill development in children with early cochlear implantation. Ear \& Hearing, 24, 59S-68S.

Hanson, V. L. (1993). Productive use of derivational morphology by deaf college students. Bulletin of the Psychonomic Society, 31, 63-65.

Kemps, R., Wurm, L., Ernestus, M., Schreuder, R., and Baayen, R. H. (2005). Prosodic cues for morphological complexity in Dutch and English. Language and Cognitive Processes, 20, 4373.

Kuo, L.-J., \& Anderson, R. C. (2006). Morphological awareness and learning to read: A cross-language perspective. Educational Psychologist, 41, 161-180.

Mahony, D., Singson, M., \& Mann, V. (2000). Reading ability and sensitivity to morphological relations. Reading and Writing, 12, 191-218.

Meyer, T. A., Svirsky, M. A., Kirk, K. I., \& Miyamoto, R. T. (1998). Improvement in speech perception by children with profound prelingual hearing loss: Effects of device, communication mode, and chronological age. Journal of Speech, Language, and Hearing Research, 41, 846-858.

Perfetti, C. A., \& Sandak, R. (2000). Reading optimally builds on spoken language: Implications for deaf readers. Journal of Deaf Studies and Deaf Education, 5, 32-50.

Robbins, A., Koch, D., Osberger, M., Zimmerman-Phillips, S., \& Kishon-Rabin, L. (2004). Effect of age at cochlear implantation on auditory skill development in infants and toddlers. Archives of Otolaryngology — Head and Neck Surgery, 130, 570-574.

Singson, M., Mahony, D., \& Mann, V. (2000). The relation between reading ability and morphological skills: Evidence from derivational suffixes. Reading and Writing, 12, 219-252. 
Applied Psycholinguistics 32:3

van Hoogmoed et al.: Deaf readers' processing of inflectional prefixes

Traxler, C. B. (2000). The Stanford Achievement Test, 9th ed.: National norming and performance standards for deaf and hard-of-hearing students. Journal of Deaf Studies and Deaf Education, $5,337-348$.

Verhoeven, L., Schreuder, R., \& Haarman, V. (2006). Prefix identification in the reading of Dutch bisyllabic words. Reading and Writing, 19, 651-668.

Vermeulen, A. M., van Bon, W., Schreuder, R., Knoors, H., \& Snik, A. (2007). Reading comprehension of deaf children with cochlear implants. Journal of Deaf Studies and Deaf Education, 12, $283-$ 302 .

Wauters, L. N., van Bon, W. H. J., \& Tellings, A. E. J. M. (2006). Reading comprehension of Dutch deaf children. Reading and Writing, 19, 49-76. 